\title{
'IT TAKES A VILLAGE': ATTAINING TEACHING EXCELLENCE IN A CHALLENGING CONTEXT
}

\author{
C. Winberg* \\ South African Research Chair: Work-Integrated Learning \\ e-mail: winbergc@cput.ac.za
}

\section{J. Garraway*}

Fundani Centre for Higher Education Development

e-mail: Garrawayj@cput.ac.za

${ }^{*}$ Cape Peninsula University of Technology

Cape Town, South Africa

\section{ABSTRACT}

The focus of this article is a teaching and learning activity system which is studied for the purpose of understanding and resolving contradictions in the system. For purposes of this study, the activity system was examined from the perspectives of university teachers and senior university managers. Data was obtained from interviews with university teachers who had expressed an interest in teaching and learning and who had demonstrated considerable ability in university teaching. Interviews were also conducted with senior managers responsible for teaching and learning at the institution. We applied the tools provided by Activity Theory (Engeström 1987; 2008) to analyse the data and propose recommendations for how university teaching might be better supported by university managers in contexts of considerable change and challenge. This required identifying and addressing areas of difficulty within and across the system for the purpose of enabling improved outcomes. In this article, areas of contradiction are analysed and constructive suggestions are made for using the identified areas of difficulty as sites for growth and development.

Keywords: university teachers, Activity Theory, teaching excellence

\section{INTRODUCTION: SYSTEMIC DISPARITIES IN THE HIGHER EDUCATION SYSTEM}

Globally, the academic profession faces many challenges, including the pressures of mass higher education, fiscal constraints, new technologies and changing attitudes towards accountability and management (Murphy 2011). In the South African context, the postapartheid expansion of student enrolment and the expectations of a society undergoing significant social change have created new roles for academic staff while challenging the coherence and viability of traditional ones. Current difficulties in South African higher 
education, such as low participation and throughput rates, are partly due to historical legacies and current practices which continue to advantage some universities and disadvantage others (Badat 2012; Bozalek and Boughey 2012). The students who attend historically disadvantaged institutions and most universities of technology are generally not adequately prepared for tertiary studies, since the majority of them come from disadvantaged educational backgrounds. While there have been funds available to redress historical imbalances, many of the difficulties experienced by under-resourced institutions are systemic and are related to broader socioeconomic factors such as disparities in staff-student ratios, access to resources and demography of the student population (Leibowitz, Bozalek, Van Schalkwyk and Winberg 2015). New management practices place additional pressures on academic staff, such as compliance-driven reporting requirements. In some cases, unrealistic targets are set for success and throughput rates. These disparities across institutions serve to perpetuate historical inequities in teaching and learning practices.

Contextual disparities impact the nature of academic work and academic staff development; for example, teaching in a poorly resourced context with large numbers of underprepared undergraduate students places considerable demands on university teachers. In such contexts, the focus of the academic staff would be primarily teaching, and they would not necessarily be expected to follow a research trajectory. In fact, in the past, many of the staff in such institutions were not expected to do research at all. Capacity development in teachingintensive contexts would need to focus on the enhancement of practice and the adoption of a scholarly and professional approach towards the responsibility of university teaching rather than on the general upgrading of qualifications, developing research capacity and publishing. Placing pressure on such lecturers to obtain a $\mathrm{PhD}$, undertake research activities and publish in accredited journals might not be appropriate in terms of their context. On the contrary, such pressure draws resources and energies away from thoughtful and engaged practice in the teaching of undergraduates (Leibowitz et al. 2015).

The focus of this study is on the contradictions across the teaching and learning system, and how this makes attaining teaching excellence difficult. The question that this article therefore addresses is: how can excellence in teaching be achieved in contexts of considerable change and challenge?

\section{ACTIVITY THEORY: A CONCEPTUAL FRAMEWORK FOR UNDERSTANDING COMPLEX SYSTEMS}

We draw on Activity Theory (Engeström 1987) to explain the contradictory goals and intentions 
of university teachers and university managers and to consider how they might be better aligned to address these contradictions. Our focus is on the contradictions within the teaching and learning activity system, and how this makes effective teaching difficult. Activity Theory provides theoretical tools for exploring complex systems. We draw, in particular, on the concept of 'contradiction' (Engeström 2008) to reveal the source of the difficulties in the teaching and learning system and its management at the university. Engeström explains that finding contradictions in an activity system provides the basis for potential problem-solving: '... contradictions manifest themselves in disturbances and innovative solutions. In this sense, an activity system is a virtual disturbance and innovation-producing machine’ (Engeström 2008, 205). Contradictions can occur within each element (primary level contradictions) or across elements (secondary level contradictions). The subjects in the activity systems will usually develop strategies to work around these contradictions, and this makes the contradictions less visible. Using the lens that Activity Theory offers, we can make the contradictions more visible and therefore more available to those concerned to address difficulties - in this case, how managers might support teachers who are striving towards excellence in their practice.

\section{RESEARCHING THE TEACHING AND LEARNING SYSTEM}

This article is part of a larger South African study funded by the South African National Research Foundation that includes eight universities. The data for this article was obtained from interviews with ten academic staff members and four senior managers at the Cape Peninsula University of Technology in Cape Town. The interview schedules were designed and piloted by the larger project team before implementation. The academic staff interviewed identified themselves, via an institutional survey, as willing to be interviewed. As a result of the selfselection process, all the interviewees had a deep interest in and commitment to university teaching. For example, the ten academic staff members who were interviewed had all been acknowledged, in different ways, for their excellence in teaching, for example, by means of national or institutional teaching excellence awards, research grants for teaching innovation, membership of faculty teaching and learning committees, or because they were departmental or faculty teaching specialists. Thus the academic staff interviewees had shown interest and ability in teaching and learning. Additional selection criteria ensured that the interviewees represented different faculties and positions (lecturers, senior lecturers, associate professors and heads of department). The Vice-Chancellor, the Deputy Vice Chancellor (DVC): Teaching and Learning and two deans of faculties, all of whom have various levels of responsibility for teaching and learning at the university, were also interviewed. All interviews were conducted 
by researchers external to the university and transcribed by a professional transcriber.

The interviews were verified by both interviewers and interviewees and coded by two researchers with in vivo coding techniques (Saldanha 2013). The project obtained ethical clearance from the lead institution, and subsequently from each participating institution. All information identifying specific individuals and their departments was removed at the stage of transcription and storage of data.

\section{RESEARCH FINDINGS: WHAT DRIVES THE ACTIVITY SYSTEM?}

In this section we report on the findings from the interviews, using the categories of activity. We start with the university teachers.

\section{University teachers: what drives the system from their perspectives?}

The overriding purpose of the teachers who were interviewed was the provision of opportunities for high-quality learning; from their perspectives, this is what drives the system. For many teachers, the act of teaching is a way of 'giving back' or 'making a difference' (Interviewee 7). Each of the interviewees spoke of their passion for teaching, but were also self-critical and always striving to do better. Critical reflection on one's own teaching practice was understood by all interviewees as central to development and growth. For the academic staff, the provision of rich learning experiences was understood to be an ideal for which one strives, a constantlyshifting goal that might be unattainable but needs to be pursued with dedication. For many, good teaching is associated with a journey, one that teacher and student embark on together. Several teachers explained this as 'learning from the students' (Interviewee 6). Good teaching is about innovation - particularly if 'doing the same thing' is not effective. Good teaching is not about 'going through the motions' (Interviewee 7) or following a set of procedures - it is about meeting students' learning needs, inspiring them, challenging them, and making a meaningful difference in their lives.

The university teachers interviewed understood that teaching in support of student learning is complex, multidimensional and in a constant state of change and development as they respond to diverse students' needs and to the changing environment. Because good teachers respond to students' needs, knowledge of students was identified as key to successful teaching. One of the interviewees described this as learning from her students:

I ... think that I'm as much a learner as I am a teacher because I learn from the students every day. I learn from them. I see teaching and learning as a communal enterprise between me and the students ... (Interviewee 6). 
All the interviewees spoke about their intention to inspire active learning and to engage students in the learning process; as one teacher put it: 'the classroom belongs to the student ...' (Interviewee 1).

\section{Tools and resources: What university teachers draw on to make a difference}

The interviewees describe two main types of resource that they draw on in striving to promote and enhance student learning: 1) experimentation and change (including the innovative use of social media and educational technologies), and 2) existing networks for teaching and learning.

While staff acknowledged the difficulties of teaching students who are underprepared for higher education, these difficulties inspired teachers to be innovative:

I think one of the biggest spurs to innovation has been a sense of frustration that I'm not being as effective as I possibly could ... and besides that it's fun to try out new things ... I just find when I have a new idea and I sit down and I start ... you know ... hammering it out on the computer I find it so inspiring .... and I often find that the students enjoy being taught in a different way to the regular chalk and talk thing. So that has been a virtuous cycle (Interviewee 2).

Another took on an additional teaching load as a personal challenge:

... the [Extended Curriculum] group that I've just volunteered for ... I'm just doing it out of my own ... I'm not getting paid for it or anything ... I'm just doing it to explore teaching using technology (Interviewee 1).

Academic staff acknowledged that there was considerable institutional provision for teaching development, but not always departmental support (or individual motivation), some academic staff members being, as one interviewee put it, content 'to rest in their comfortable chair of mediocrity' (Interviewee 2). Most of the interviewees were aware of professional development opportunities, but pointed out that development did not only occur through formal training but through reading, interacting with colleagues, participation in teaching and learning conferences (Interviewee 2), national interest groups (Interviewee 9), and involvement in educational research:

... a huge influence on my teaching I must say has been this whole scholarship of teaching, of reading, of understanding, of you know, trying to see why are the students doing this ... reading books ... reading articles (Interviewee 6).

There was general support for faculty teaching and learning structures:

... another great influence is the [Faculty] Teaching and Learning committee ... that's the great influence on my teaching (Interviewee 6). 
There was similar support for the 'embedded' teaching and learning or academic literacy experts in departments as enablers. Several interviewees spoke about team-teaching with a colleague, such as a communication or academic literacy lecturer, as a way of developing themselves:

... I have had joint classes with the academic literacy lecturer previously on giving the piece of text background to a topic ... and then I go through the scaffolded reading exercise on it ... that whole notion of scaffolding a concept ... [I have] incorporated it into my own methodologies (Interviewee 4).

\section{Rules, institutional cultures and the distribution of labour}

Academic staff understood that the institution was a teaching-intensive university and that research outputs were important for its credibility, but emphasised the need for an appropriate balance. Some interviewees felt that, although there was a strong drive for staff to obtain PhDs in their disciplines, teaching qualifications were less valued. Several staff members felt that the undervaluing of teaching was evident in management practices, such as inadequate staffing in relation to the intensive teaching required in many departments:

... staff who leave aren't being replaced and so we would have ... a few years ago ... had a bigger staff structure ... and that allowed for ... more time for development for the staff but it also allowed more time for them to do reading ... preparation and ... assessment (Interviewee 9).

Many programmes are accredited or reviewed by professional bodies, and staff felt that the professional status of the programmes provided concomitant status to teachers in such programmes. However, it placed an additional burden on the academic staff, one that was not always acknowledged; as one staff member put it: ' ... keeping up-to-date in the profession in the department is huge' (Interviewee 9).

Academic staff did not expect to be rewarded for good teaching; for many, it was a matter of personal pride and professionalism. One staff member felt that striving for teaching excellence was 'more beneficial for my own development than for that of the university' (Interviewee 4).

While there was no shortage of ideas, inspiration and opportunities, interviewees felt that some staff lacked the confidence to put themselves forward or to request opportunities to improve their teaching. From academic staff members' perspectives, supportive heads of department played a crucial role in enabling their development as university teachers. One of the interviewees (himself a departmental head) explained: 
The HODs have to balance a number of things of course ... their concerns are slightly different to somebody who is purely a teaching and learning person because they have to deal with logistics and the administration and finance and human resources ... but I think most of them are very positive about teaching initiatives and very supportive of good teaching initiatives ... they do tend to question very closely the means and the costs and the feasibility ... but I think they are very supportive ... as a manager I feel one of the key things I must do is try to provide an enabling and supportive environment ... (Interviewee 2).

Staff with supportive heads of department, as the following interviewee explained, considered themselves fortunate:

I consider myself very lucky in that regard because I am free to go and disagree with my Head of Department in principle and say to him I know you're the Head of Department and I know you will have the final say but my view on this or that is ... (Interviewee 5).

The following interviewee explained different experiences with supportive and non-supportive heads of department:

I had a lot of support from the previous HOD who really was trying to understand teaching and learning and working towards it and ... went with me to conferences and wrote papers together to present ... so that was a tremendous support and it was nice because it's the first time I had experienced that ... but then that HOD left and we got another HOD who knows nothing about teaching and learning and quite honestly is not interested ... (Interviewee 6).

For academic staff, the most significant constraint to their engagement in academic development was a head of department who was unable to provide teaching and learning leadership or support:

... the HOD ... does not know much about [teaching and learning] but is ... [expected] to implement it ... so this is where the problem lies ... (Interviewee 8).

The issue of staff morale appeared to be a barrier to the uptake of development opportunities. Some academic staff members, who were interested in developing their teaching, found themselves in a department with colleagues who were not like-minded. Their situation was often exacerbated by a lack of teaching and learning leadership, which created what one staff member called 'a very toxic department'. Clearly, in such stressful conditions, there is little hope of attaining teaching excellence.

Academic staff pointed out that, while there were enabling policies and institutional structures, departmental practices often ignored institutional guidelines. As one staff member put it, 'They say the right things [but] what they say and what they do are two different things' 
(Interviewee 4). Some of the staff were sceptical about the effectiveness of institutional systems and structures. A major constraint identified by academic staff was the administrative burden placed on them:

One of the reasons why I think the staff do not use opportunities to improve their teaching is because of all the demands ... administrative demands ... we spend most of our time uploading marks ... downloading marks ... checking registrations ... if we can improve our systems and we can give staff more time to focus on teaching and learning ... we as a teaching institution will be much better (Interviewee 3).

Staff complained that their extremely heavy workloads prevented them from taking up staff development opportunities: 'workloads are just prohibitive ... workloads and marking ...' (Interviewee 4).

Interviewees and questionnaire respondents generally complained about the burden placed on them, the result of a lack of adequate building maintenance and poor IT infrastructure:

... we are so caught up with operational matters that there is never is enough opportunity to speak about the teaching and learning issues (Interviewee 3).

Some staff felt that the 'constantly changing regulatory framework in South African higher education', far from creating opportunities for staff development, was a barrier and an unnecessary burden on academic staff:

Now, I've been through previous re-curriculation exercises which were a fraction of the bureaucratic, technocratic complexity ... there were vast and complex bureaucratic ramifications and a number of forms that have to be filled in ... such that it was hard to think about what's going into the curriculum ... which is what you should be ... rather than which documents that you have fill in ... what are the deadlines and so on ... and your business plan (Interviewee 2).

Issues such as the poor state of facilities and the maintenance of buildings consume the time and energy of academic staff, which might otherwise have been used to improve teaching and learning:

... we have very poor facilities and ... we've been taking it up ... everywhere and anywhere we can. We have compiled reports ... our facilities are just ... it's poor ... I've taken photos ... we've sent it in ... we've asked for equipment ... and we're hoping ... we're always hoping ... just that environment will go a long, long way ... I mean we sit with empty cold classrooms with no blinds and no ... some places not even a whiteboard ... I'm not even talking about data projectors and things like that ... we're trying to make do with what we've got ... but there's a big problem with the infrastructure (Interviewee 1).

Much of the academic staff's energy tends to go into working around the dysfunctionality: 
You know little things ... you want a light replaced in the classroom ... eventually I get a student to climb up on the ladder and put it in you know because ... it's quicker ... so we have to solve problems ... I don't for a moment believe that ... it's reached the stage where it interferes grossly ... I think they're hurdles and we have to overcome them and that's it ... then we solve it ourselves and you know there are budget limitations there are maintenance limitations and things ... but we have a really nice campus ... it's clean ... it's well maintained ... I am proud of it ... so I think the students have a nice environment to learn in ... I think we have a nice environment to operate in and for that I'm really grateful ... because I think learning in anything less is really hard (Interviewee 9).

Several staff members explained the challenges in developing teaching methods, or in trying out new approaches, when there were insufficient resources or facilities for implementing innovative practices:

There's one data projector in a department and even if you do manage to find a data projector, the venues are not such that you can easily use a data projector ... you have to cart it from one venue to the next ... In order to do the kind of developmental work that I am requested to do I also need physical facilities and those physical facilities are not forthcoming ... we are in the process of improving our infrastructure ... it takes time but I do not want the quality of my teaching and student learning to be hindered by something like infrastructure ... to the extent that the student can’t learn optimally (Interviewee 3).

\section{THE MANAGERS: MEETING THE OUTPUT TARGETS}

In this section, the perspectives of the senior managers of the institution, in terms of the categories of activity, are identified.

\section{Object: What drives the system from senior managers' perspectives?}

Senior managers tried to drive the teaching and learning system predominantly by targets and outputs; thus good teaching was understood in terms of satisfactory throughput and pass rates:

The [South African Department of Higher Education and Training] asked us ... to stretch ourselves more and set ourselves more challenging targets ... we had 78 ... 79\% nine percent ... they set us a target of $80.1 \%$... in our three year rolling planning cycle and ... so we addressed that through our review processes on an annual basis (Senior Manager 2).

\section{Tools: what managers draw on to make the system work}

Managers felt that policies, incentives, teaching awards and compulsion were the means by which good teaching (understood as meeting targets) could be achieved. Managers assumed that meeting these targets, was relatively straightforward, although they acknowledged the heavy demands on the academic staff: 
First you have to say to yourself what are the skills that I want the student to achieve? ... how [do] we package what ... our students need to learn so that we can put down a specific learning unit ... which is forty hours? ... ... what are the activities of the lecturers? ... what are the activities of the students? ... what are the assessment criteria? ... (Senior Manager 3).

The senior managers interviewed acknowledged that improving the status of teaching was important at a teaching-intensive university, but was difficult because it had to compete with research recognition:

... and that is the issue, it sits around what sort of incentives are there for staff ... in our promotions criteria we are starting to place much more emphasis on the teaching and learning and ... we have included sub-minimum scores for ratings, for promotion to associate professorship ... so it is possible for staff to attain the position of an associate professorship with a strong teaching and learning portfolio ... (Senior Manager 2).

Managers felt that conferring 'compulsory' status on the training of new staff (who were required to attend a one-semester part-time teaching development programme) raised the profile of teaching in the institution. For one of the senior managers (4), the status of teaching was related to the status of university staff generally - and of particular importance was attracting staff with strong research profiles to teaching.

Senior managers recognised the institution's responsibility to provide staff development and claimed that 'various methods of academic support for both lecturers and students has always been part of what we do' (Senior Manager 1). Senior managers understood the policy environment and the allocation of appropriate resources for the uptake of professional development opportunities, particularly for 'academics who really want to push the frontiers in this area’ (Senior Manager 2). Senior managers also recognised that heads of department played a key role:

... heads of academic departments are not there as administrative clerks ... they are there to oversee that the academic project is delivered and delivered well and that ... the academics ... get the necessary support (Senior Manager 1).

\section{Rules, institutional cultures and the distribution of labour}

The need to provide an enabling policy environment and institutional structures that support high-quality teaching was noted by most of the managers interviewed. Institutional processes, such as 'subject reviews' (which require academic staff to reflect and report on subject pass rates) created opportunities for staff to review their teaching. Senior managers expressed an understanding of some of the difficulties that academic staff face with regard to engaging in professional development. According to one senior manager, the institution is 'burdened with 
numbers':

I think the impediments ... speak to student numbers ... the student-lecturer ratios at our institution are still fairly high and so the interventions sometimes although positive ... the numbers may militate against that (Senior Manager 1).

Thus, heavy teaching loads are a barrier to staff participation in academic development. In addition, the volume of work associated with the consolidation of faculties leaves little time or energy for staff development:

The merger has made us all very, very tired and so we have been too tired to spend time on teaching development ... (Senior Manager 3).

Senior managers recognised that, while many heads of department supported teaching and learning, there were others who were not particularly enthusiastic about teaching or about developing academic staff for teaching, and who were therefore a barrier to the uptake of staff development:

... there are a number of HODs [who] are more research-focused ... who don't really see teaching and learning as the main issue in the department ... so it is a challenge ... and from my position ... I speak to the Deans ... I try to emphasize this and the Deans are supportive but you know there is a limit to what you can do if you don't have ... the cooperation of all the staff ... so there are challenges (Senior Manager 2).

As an institution without a long research tradition, some managers felt that research was important for the institution's credibility and that the researchers therefore deserved reward and recognition, while teaching was more commonplace, and was therefore not rewarded, or rewarded less. Thus there was a sense emerging that heavy teaching loads could be regarded as a 'punishment' for those who did not produce research outputs. However, there were also cases where heads of department wanted to implement innovative teaching and learning practices, while academic staff 'in their comfort zones' ‘derail[ed]' such initiatives (Senior Manger 4).

While most senior managers felt that the structures and systems (e.g., committee structures, the subject review mechanism) were generally supportive of staff development for teaching and learning, one manager felt that the structures played more of a constraining role:

... it's the lethargic nature of academic institutions ... everything revolves around committees and lengthy meetings and nothing gets anywhere and logic doesn't always prevail ... you're guided by policies and the policies eventually become laws ... the policy is there to guide not regulate ... (Senior Manager 4). 


\section{DISCUSSION: CONTRADICTIONS IN THE SYSTEM - AND HOW TO ADDRESS THEM}

In this section, we explain the contradictions across the system (see Figure 1) and suggest ways in which they might be addressed. As is evident in the descriptions above, there are currently numerous contradictions in the system, which are not conducive to the attainment of good teaching. These contradictions exist at both the primary level (i.e., within elements, such as staff and manager's different understanding of the object) and at the secondary level (i.e., across elements such as the disjunction between rules and object). There are additional tertiary contradictions, for example, between the DHET and the university's teaching and learning system, but these are beyond the scope of this article (although they clearly have an influence on individual university activity systems).

The first and most important contradiction, from which most of the other contradictions arise, is that there are different understandings of the object, or what drives the teaching and learning system; this is the key contradiction shown in Figure 1. For the managers, it is the targets set by the DHET and their related subsidies, while for the teachers it is the quality of student learning. While teachers agree that improving the pass rate and the throughput rate is important, they understand that this is the natural outcome of high quality student learning. Senior managers have conflated the object of the system with the outcome of the system. Similar conflations of object with outcome are common in systems that are driven by outside market forces rather than by the development and well-being of subjects; it is what Engeström (1987) calls the 'fundamental contradiction of capitalist life'.

University teachers experience the contradictions at all levels of the system, particularly in having to carry the burden of managerialist policies and in doing the work of administrative and maintenance service departments that do not function well, or that do not have the capacity to do advanced administrative work. Teachers therefore expend time and energy that could be used in more constructive ways.

While institutions need clear processes and support for the implementation of teaching and learning policies (Trowler and Bamber 2005), some of the contradictions around the division of labour could be addressed if there were clear lines of responsibility and accountability and sanctions for their non-implementation. Such policies exist, but the policy 


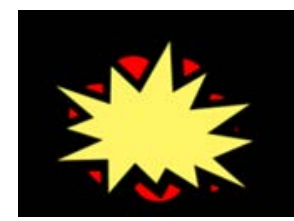

Tools \& Resources that make a difference

Teachers: experimentation \& innovation, existing networks.

Managers: incentives, awards, compulsion

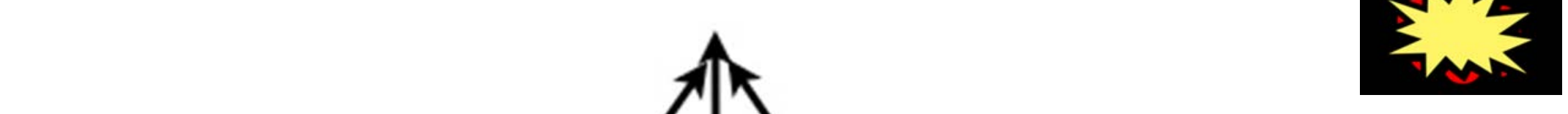

What drives the system? Teachers: high quality student learning and development Managers: Outputs, throughputs, subsidy

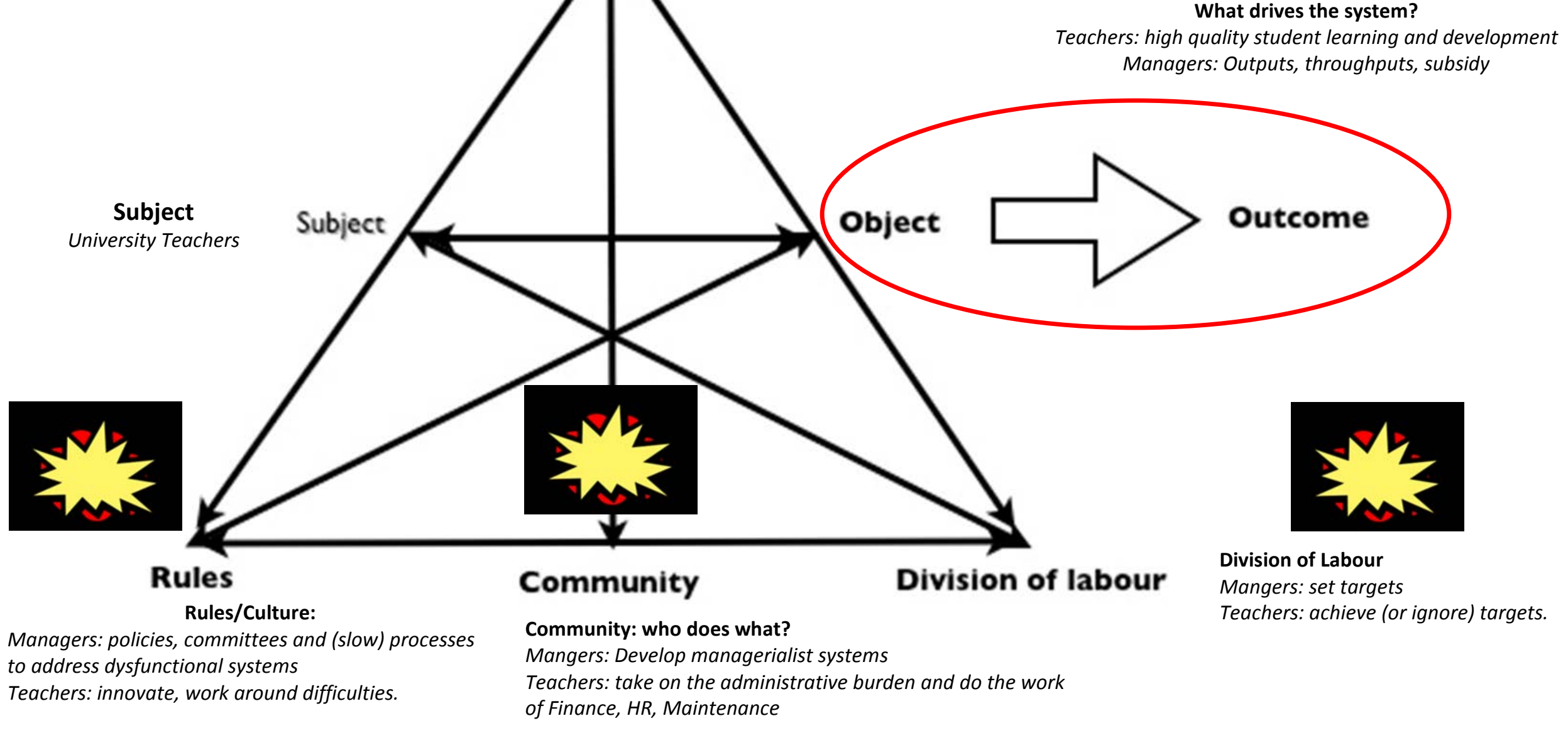

Figure 1: Primary and secondary contradictions the teaching and learning activity system 
'implementation gap' needs to be addressed in ways that are sensitive to disciplinary and professional cultures (Trowler and Wareham 2008), emphasising the guiding rather than the 'policing' role of enabling structures (Boud and Brew 2013).

Clearly, the institution needs to address failing service and support systems, as is shown by the long list of interviewees' complaints with regard to IT infrastructure, building maintenance, excessive amounts of administrative work, and so on. A dysfunctional context places a significant burden on academic staff, and teaching and learning suffers. It might be helpful to quantify the impact of the lack of support on the quality of teaching and learning (e.g., the amount of down-time caused by the lack of WiFi access, or by compliance-driven quality assurances processes). The 'human element' (Blix, Cruise, Mitchell and Blix 1994), such as the distress experienced by academic staff related to mergers and the significant additional workload imposed by re-curriculation and other projects (over and above generally high workloads), requires senior managers' attention. Many heads of department, as Senior Manager 2 pointed out, are 'research-focused' and do not value 'teaching and learning as the main issue in the department'. A recommendation resulting from this study is, therefore, that departmental heads should, in addition to showcasing their research achievements, also highlight university teachers' successes in teaching and learning.

Implementation of the above suggestions might help to start the long process of changing perceptions around the 'second class' status of teaching at the university, and some of the worrying contradictions that seem to be emerging in the institutional culture, such as giving excellent teachers additional teaching loads because they are not doing research.

Most of these difficulties arise from senior managers substituting throughput targets for the quality of student learning as the object of the teaching and learning system. Buller (2015) suggests that an 'iron triangle' occurs where there are three powerful forces, but only two can be easily attained. In this regard, it is extremely difficult to maintain a balance between teaching inputs (such as innovative teaching), teaching outputs (such as a high student throughput rate) and the quality of those outputs. For example, while it is possible to reduce teaching inputs (by placing non-teaching related burdens on teaching staff or reducing the number of staff in the system) and to increase student throughputs, it is unlikely that the quality of the student outputs will increase.

Similarly, it is possible to increase student outputs and the quality of these outputs, but not with reduced teaching inputs and resources. Trying to manage by outcomes ('the bottom line') doesn't work in higher education because academic staff are not 'machines for producing student outcomes' (Buller 2015). Expertise is distributed in higher education and the role of university leadership is to build a culture of excellent teaching and, in this way, to enhance the 
quality of student learning. Academic staff, particularly those who have attained excellence in teaching and learning, should be regarded as valued colleagues who share a common and very complex educational project. In the words of the well-known African proverb: 'It takes a village to raise a child' - to which we would add '... and it takes a dedicated team of engaged, scholarly and passionate university teachers, supported by their managers, to change a failing teaching and learning system'. Managers need to provide consistent, not contradictory, support for academic staff in their roles as teachers. Student outcomes will flow from this.

\section{ACKNOWLEDGEMENT}

The South African National Research Foundation (project leader: Professor Brenda Leibowitz) provided funding for the project titled ‘Context, structure and agency’ (grant no: 90353).

\section{REFERENCES}

Badat, S. 2012. Redressing the colonial/apartheid legacy: Social equity, redress, and higher education admissions in democratic South Africa. In Equalizing access: Affirmative action in higher education in India, United States, and South Africa, ed. Z. Hasan and M. Nussbaum, 121-150. New Delhi: Oxford University Press.

Blix, A. G., R. J. Cruise, B. M. Mitchell and G. G. Blix, 1994. Occupational stress among university teachers. Educational Research 36(2): 157-169.

Boud, D. and A. Brew 2013. Reconceptualising academic work as professional practice: Implications for academic development. International Journal for Academic Development 18(3): 208-221.

Bozalek, V. and C. Boughey. 2012. (Mis)Framing Higher Education in South Africa. Social Policy and Administration 46(6): 688-703.

Buller, J. L. 2015. Change leadership in higher education. San Francisco, CA: Jossey-Bass.

Engeström. Y. 1987. Learning by expanding: An activity-theoretical approach to developmental research. Helsinki, Finland: Orienta-Konsultit.

Engeström, Y. 2008. From teams to knots: Activity theoretical studies of collaboration and learning at work. Cambridge: Cambridge University Press.

Leibowitz, B., V. Bozalek, S. van Schalkwyk and C. Winberg, 2015. Institutional context matters: The professional development of academics as teachers in South African higher education. Higher Education 69(2): 315-330.

Murphy, M. 2011. Troubled by the past: History, identity and the university. Journal of Higher Education Policy and Management 33(5): 509-517.

Saldana, J. 2013. The coding manual for qualitative researchers. (2nd Edition). Berkley, CA: Sage Publications.

Trowler, P. R. and V. Bamber. 2005. Compulsory higher education teacher education: Joined-up policies; institutional architectures; enhancement cultures. International Journal for Academic Development 10(2): 79-93.

Trowler, P. R. and T. Wareham, 2008. Tribes, territories, research and teaching: Enhancing the teaching-research nexus. Working Paper. The Higher Education Academy, York. 